\title{
Ocorrência de doenças infecciosas em gatos do Planalto Catarinense
}

\author{
Occurrence of infectious diseases in cats from Catarinense Plateau
}

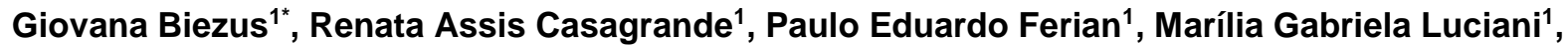 \\ Juliana Regina de Souza ${ }^{2}$, Suelen Dal Pozo ${ }^{3}$, Cristiane Borges Vargas ${ }^{1}$ \& Thierry Grima de Cristo ${ }^{1}$ \\ ${ }^{1}$ Universidade do Estado de Santa Catarina, Lages, SC, Brasil. *Autor para correspondência: giovanavet@live.com. \\ 2 Veterinária Autônoma, Jaraguá do Sul, SC, Brasil. \\ ${ }^{3}$ Veterinária Autônoma, Curitiba, PR, Brasil.
}

Submissão: 16/10/2016 / Aceite: 09/05/2018

\begin{abstract}
RESUMO
Os gatos estão entre os animais de estimação mais comuns no mundo inteiro e é cada vez mais estreito o seu convívio com os humanos, o que torna os estudos epidemiológicos relativos às doenças que afetam essa espécie de grande importância. Portanto, este trabalho teve como objetivo determinar a ocorrência de doenças infecciosas em gatos atendidos no Hospital de Clínicas Veterinárias (HCV) da Universidade do Estado de Santa Catarina (UDESC), no município de Lages, assim como identificar os principais sinais clínicos apresentados por cada uma destas. Para isso, foram revisados 825 prontuários de consultas clínicas de gatos, arquivados no HCV, do período de fevereiro de 2013 a julho de 2015. Dentre os prontuários revisados, $20 / 825(2,42 \%)$ apresentaram diagnóstico definitivo de doenças infecciosas. A distribuição das enfermidades classificadas como infecciosas foram as seguintes: virais 12/20 (60,00\%); bacterianas $4 / 20(20,00 \%)$; fúngicas $3 / 20(15,00 \%)$ e causadas por protozoário $1 / 20(5,00 \%)$. Dentre as doenças infecciosas, a mais ocorrente foi com o vírus da leucemia felina (FeLV) [12/20 (60,00\%)], cujas manifestações clínicas encontradas foram a anemia $[6 / 12 \quad(50,00 \%)]$, seguida pela leucemia [4/12[(33,33\%)] e pelo linfoma [2/12(16,67\%)]. Também foi obtida a ocorrência das doenças infecciosas de acordo com alguns critérios de seleção, como raça, idade, sexo, acesso à rua, contato com outros animais e status de vacinação. Gatos machos, não vacinados, com acesso livre à rua e contato direto com outros felinos estiveram em maior número dentre os doentes, o que demonstra a íntima relação da falta de cuidados básicos de saúde desses animais com a ocorrência das doenças infecciosas na espécie.
\end{abstract}

PALAVRAS-CHAVE: FeLV, vírus, felinos, agentes infecciosos.

\section{ABSTRACT}

Cats are among the most common pets in the world. The close relationship between human beings and cats supports the importance of epidemiologic studies on feline diseases. Therefore, this study showed the occurrence of infectious diseases in cats at the Veterinary Clinics Hospital (HCV) of Santa Catarina State University (UDESC), in Lages (SC, Brazil), as well as identifying the major clinical signs presented in each affection. Hence, 825 medical records were reviewed, from February 2013 to July 2015. Among the reviewed records, $20 / 285(2,42 \%)$ were diagnosed with infectious diseases. The distribution of infectious diseases was: viral 12/20 (60,00\%); bacterial 4/20 (20,00\%); fungal $3 / 20(15,00 \%)$ and caused by protozoa $1 / 20(5,00 \%)$. Among these infectious diseases, the most diagnosed agent was Feline Leukemia Virus (FeLV) [12/20 (60,00\%)]. The most observed clinical signs were anemia $(6 / 12[50,00 \%])$, followed by leukemia $(4 / 12[33,33 \%])$ and lymphoma $(2 / 12[16,67 \%])$. The study also showed the occurrence of infectious diseases according to some selection standards, for instance, breed, age, sex, outdoor access, inhabiting with other pets and vaccination status. The most affected group of animals were non-vaccinated male cats, which had direct contact with other felines and outdoor access, demonstrating the close relationship between the lack of health care and the occurrence of feline infectious diseases.

KEYWORDS: FeLV, virus, feline, infectious diseases.

\section{INTRODUÇÃO}

Os gatos estão presentes em $17,7 \%$ dos domicílios brasileiros, sendo o segundo animal de estimação com maior contato direto com os seres humanos (IBGE 2015). Apesar deste fato, poucos 
estudos são realizados sobre os aspectos epidemiológicos das doenças infecciosas que acometem estes felinos. Acredita-se que o nível de conhecimento da população sobre a guarda responsável de gatos está estritamente relacionado com a frequência de doenças infectocontagiosas na espécie (LANGONI et al. 2011). Portanto, um estudo epidemiológico acerca das doenças que acometem os gatos de certa população representa um importante papel na manutenção da saúde pública (ALVES et al. 2005), sendo que estes estão cada vez mais inseridos no ambiente doméstico.

Dentre os agentes infecciosos, os vírus são responsáveis por um grande número de animais doentes na rotina da clínica veterinária (DEZENGRINI et al. 2007). A leucemia felina, é uma das doenças virais mais citadas na literatura. O vírus da leucemia felina (FeLV) é responsável por causar grande número de óbitos, por meio da manifestação de imunossupressão, anemia arregenerativa, linfoma e leucemia (LUTZ et al. 2009). As doenças bacterianas são de grande importância nos felinos, atuando como agente primário da infecção ou como doença concomitante. Dentre as principais doenças bacterianas, pode ser citada a micoplasmose felina ou anemia infecciosa felina, causada principalmente por Mycoplasma haemofelis, responsável por causar anemia hemolítica nos gatos infectados (TASKER 2010).

Algumas doenças fúngicas são comuns em gatos, como a criptococose; outras, como a histoplasmose, apresentam menor ocorrência (JANG \& WALKER 2006). A criptococose é uma micose sistêmica e potencialmente fatal, de distribuição mundial, que pode ser encontrada em um grande número de mamíferos (QUEIROZ et al. 2008, MARTINS et al. 2008). Essa enfermidade é causada pelo fungo Criptococcus neoformans, sendo as variedades $C$. neoformans e $C$. gattii as mais relatadas como agentes infecciosos em gatos (GUNN-MOORE \& REED 2011, TRIVEDI et al. 2011). Nos felinos, os sinais clínicos associados a essa doença são variáveis e, apesar das formas respiratória e cutânea serem as apresentações mais comuns da doença, pode ser encontrado ainda acometimento ocular e, mais raramente, do sistema nervoso central (CASTELLÁ et al. 2008, PENNISI et al. 2013).

A histoplasmose ocorre em felinos infectados pelo fungo Histoplasma capsulatum (SYKES \& TABOADA 2014). Sabe-se que a histoplasmose é de maior ocorrência em climas temperados e subtropicais (BRÖMELL \& SYKES 2005), porém a literatura consultada expressa poucos dados epidemiológicos com relação a essa doença nos gatos. Os sinais clínicos são variáveis, podendo se apresentar na forma cutânea ou disseminada da doença, com acometimento pulmonar, do sistema nervoso central, linfoadenomegalia e hepatoesplenomegalia (KERL 2003). Além destas, outras doenças virais, fúngicas, bacterianas e parasitárias podem comprometer a saúde do paciente felino.

Baseado no fato de que, na literatura consultada, são escassos os dados epidemiológicos sobre as doenças infecciosas que afetam os gatos no país, o objetivo deste trabalho foi determinar quais são as doenças infecciosas que mais acometem os gatos atendidos no Hospital de Clínicas Veterinárias (HCV) da Universidade do Estado de Santa Catarina (UDESC), além de relacionar as principais formas de apresentação clínica e alterações hematológicas.

\section{MATERIAL E MÉTODOS}

Foram revisados os prontuários clínicos dos felinos domésticos atendidos no pronto-atendimento do Hospital de Clínicas Veterinárias (HCV) da Universidade do Estado de Santa Catarina (UDESC), no período de fevereiro de 2013 a julho de 2015, totalizando 825 prontuários. Foram incluídos, neste estudo, felinos oriundos de municípios da região do Planalto Catarinense. Dos dados obtidos, foram selecionados os que possuíam diagnóstico definitivo de doenças infecciosas, sendo então compilados em tabela (Excel). Junto com o diagnóstico clínico, dados complementares, como a raça, a idade, o sexo, a utilização de vacinas, o modo de vida do animal, os sinais clínicos apresentados e o desfecho clínico da doença, foram obtidos. Os diagnósticos foram obtidos pelo médico veterinário responsável pelo atendimento e fundamentados por meio da análise dos exames laboratoriais, dos sinais clínicos e da evolução da doença. Fizeram parte deste estudo, somente casos com diagnóstico definitivo obtido por exames, como imunofluorescência indireta, avaliação histopatológica, cultura bacteriana e exame coproparasitológico. Os casos não fundamentados foram excluídos.

Com relação aos dados complementares, os felinos foram classificados da seguinte maneira: quanto à raça, foram classificados como sem raça definida (SRD) ou com a sua raça específica; com relação ao gênero, foram classificados como macho ou fêmea; quanto à idade foram divididos em menores que 1 ano, entre 1 a 7 anos e acima de 7 anos, seguindo o critério de classificação para gatos geriátricos aqueles acima de 7 anos (FORTNEY 2008). Os gatos também foram classificados quando aos seus hábitos de vida e cuidados preventivos: vacinados ou não; desverminados ou não; se possuem acesso livre à rua ou não, e se possuem contato direto com outros felinos. Também foram obtidos dados sobre o desfecho da doença, 
para esses animais.

Após a classificação, foi obtida a ocorrência de cada enfermidade para cada um dos critérios de classificação supracitados, assim como a obtenção das principais alterações hematológicas e dos sinais clínicos encontrados.

\section{RESULTADOS}

Dos 825 atendimentos de gatos, no período de fevereiro de 2013 a julho de $2015,20(2,42 \%)$ tiveram diagnóstico definitivo de doença infecciosa e fazem parte deste estudo. A ocorrência obtida para cada critério de classificação pode ser visualizada na Tabela 1.

Tabela 1. Ocorrência de gatos diagnosticados com doenças infecciosas para cada critério de classificação. Table 1.Occurrence of diagnosed cats with infectious diseases according to each classification criteria.

\begin{tabular}{lll}
\hline Critérios de classificação & & Ocorrência \\
\hline Raça & SRD & $19 / 20(95,00 \%)$ \\
& Siamês & $1 / 20(5,00 \%)$ \\
\hline Idade (anos) & $\leq 1$ & $8 / 20(40,00 \%)$ \\
& $>1 \leq 7^{*}$ & $12 / 20(60 \%)$ \\
\hline Gênero & Macho & $14 / 20(70 \%)$ \\
& Fêmea & $6 / 20(30 \%)$ \\
\hline Status de vacinação & Vacinado & $0(0,00 \%)$ \\
& Não vacinado & $20 / 20(100 \%)$ \\
\hline Quantidade de gatos no domicílio & 1 & $7 / 20(35 \%)$ \\
& $>1$ & $13 / 20(65 \%)$ \\
\hline Acesso livre a rua & Sim & $17 / 20(85 \%)$ \\
& Não & $3 / 20(15 \%)$ \\
\hline Óbito & Sim & $13 / 20(65 \%)$ \\
& Não & $7 / 20(35 \%)$ \\
\hline
\end{tabular}

SRD: sem raça definida; *média 2 anos e 1 mês.

Dentre os casos que se encaixaram nos critérios para este estudo, $12 / 20$ (60,00\%) foram diagnosticados com o vírus da leucemia felina. Com doença bacteriana, foram diagnosticados quatro casos [4/20 (20\%)]; destes, 3/20 (15\%), com anemia causada pelo Mycoplasma spp., e 1/20 (5\%), com enterite bacteriana por Clostridium perfringens. Foram diagnosticados com doenças fúngicas, como a criptococose e a histoplasmose, três casos [3/20 (15\%)]. Com doença causada por protozoário (Giardia sp.), foi diagnosticado um caso [1/20 (5\%)].

$\mathrm{Na}$ Tabela 2, pode ser visualizada a ocorrência da infecção por FeLV, de acordo com os critérios de classificação. O FeLV foi diagnosticado em felinos com idade de 2 meses até 7 anos, com uma média de idade de 1 ano e 10 meses. A principal manifestação clínica encontrada foi a anemia [6/12 (50,0\%)], seguida pela leucemia [4/12 (33,33\%)] e pelo linfoma [2/12 (16,67\%)]. Foram submetidos à avaliação hematológica nove gatos, nos quais a anemia arregenerativa [4/9 (44,44\%)] e as alterações hematológicas sugestivas de leucemia [4/9 (44,44\%)] foram as mais ocorrentes, sendo que a leucopenia intensa esteve presente em um caso $(11,11 \%)$. Dos 12 casos de FeLV, nove $(75,0 \%)$ diagnósticos foram realizados por meio de imunofluorescência indireta de amostras de sangue obtidas com o paciente ainda vivo e três (25,00\%) suspeitos foram confirmados por exame anatomopatológico após o óbito.

Com relação às doenças bacterianas, os três felinos que apresentaram anemia causada por Mycoplasma spp. não possuíam raça definida, eram adultos, machos, não vacinados, possuíam contato direto com outros felinos e tinham acesso livre à rua. Os principais sinais clínicos foram as mucosas pálidas [3 (100\%)] e anorexia [2 (66,67\%)]. As alterações hematológicas foram anemia regenerativa e estruturas compatíveis com Mycoplasma sp., no esfregaço sanguíneo. O felino que apresentou enterite bacteriana não tinha raça definida, era adulto, fêmea, não vacinado, vivia em contato com outros felinos e mantinha acesso livre à rua. A manifestação clínica foi a diarreia profusa de odor fétido e, no hemograma, apresentava leucocitose e neutrofilia. O diagnóstico de enterite por Clostridium perfringens foi obtido meio da cultura do material fecal.

Os gatos que apresentaram doenças fúngicas não possuíam raça definida, não eram vacinados, tinham contato com outros felinos e acesso livre à rua [3 (100\%)]. Dois destes eram adultos e apresentaram criptococose [2/3 (66,66\%)], e um jovem [1/3 (33,34\%)], com histoplasmose. Os casos de criptococose foram caracterizados na forma da doença disseminada, com acometimento de linfonodos, pulmão e sistema 
nervoso central, e o desfecho para os dois casos foi o óbito. Em ambos os felinos com criptococose, foi realizado hemograma, cuja principal alteração encontrada foi a neutrofilia, com desvio à direita. O felino com histoplasmose apresentou ferida ulcerada na região do plano nasal. $O$ diagnóstico de criptococose foi realizado pela caracterização do fungo pelo método de citologia aspirativa por agulha fina de linfonodos mandibulares com o animal ainda vivo e, após o óbito, por avaliação histopatológica. No caso da histoplasmose, foi realizada a detecção do fungo por citologia aspirativa por agulha fina e cultura micológica.

O felino que apresentou doença causada por protozoário foi diagnosticado com enterite parasitária por Giardia sp. Era uma fêmea, adulta, sem raça definida, não vacinada, mantinha contato com outros felinos e possuía acesso livre à rua. Apresentou frequência de defecação aumentada, com diarreia de aspecto mucoso. O diagnóstico de Giardia sp. foi obtido pelo exame coproparasitológico.

Tabela 2. Ocorrência do FeLV em gatos de acordo com cada critério de classificação.

Table 2. Occurrence of FeLV in cats according to each classification criteria.

\begin{tabular}{lll}
\hline Critérios de classificação & & FeLV $(\%)$ \\
\hline Raça & SRD & $11 / 12(91,67 \%)$ \\
& Siamês & $1 / 12(8,33 \%)$ \\
\hline Idade & $\leq 1$ & $3 / 12(25,00 \%)$ \\
& $>1 \leq 7$ & $9 / 12(75,00 \%)$ \\
\hline Gênero & Macho & $10 / 12(83,33 \%)$ \\
& Fêmea & $2 / 12(16,67 \%)$ \\
\hline Uso de vacinas & Sim & $0 / 12(0 \%)$ \\
& Não & $12 / 12(100 \%)$ \\
\hline Acesso livre à rua & Sim & $10 / 12(83,33 \%)$ \\
& Não & $2 / 12(16,67 \%)$ \\
\hline Contato direto com outros gatos & Sim & $7 / 12(58,33 \%)$ \\
& Não & $5 / 12(41,66 \%)$ \\
\hline Óbitos & & $11 / 12(91,67 \%)$ \\
\hline
\end{tabular}

$\overline{\mathrm{SRD}}=$ sem raça definida; FeLV = vírus da leucemia felina.

\section{DISCUSSÃO}

De maneira geral, a prevalência de doenças infecciosas na população em estudo é baixa; porém, na rotina da clínica veterinária, existem algumas limitações no diagnóstico definitivo de algumas doenças infecciosas, dentre as quais a falta de recursos financeiros e tecnológicos. Não foram encontrados, na literatura consultada, estudos similares. Corroborando estes resultados, em um levantamento avaliando as causas de óbito e as razões para eutanásia em uma população hospitalar de gatos, as doenças infecciosas também não foram consideradas relevantes (TRAPP et al. 2010).

Neste estudo, foi possível observar maior ocorrência das doenças infecciosas nos felinos SRD, de 1 a 7 anos (média de 2 anos e 1 mês), não vacinados, com livre acesso à rua, e que habitam o mesmo domicílio com outros gatos. Com relação à raça, não é possível tirar conclusões, pois a população de felinos atendida no HCV é constituída, em grande parte, por felinos SRD. Já os demais fatores em associação facilitam a disseminação de doenças infecciosas e também refletem a falta de cuidados básicos de saúde com estes animais (LANGONI et al. 2011).

Dentre as doenças infecciosas, as causadas por vírus foram a de maior ocorrência. $O$ fato se deve ao baixo índice de vacinação dos gatos, associado ao acesso livre à rua e ao contato com outros felinos. Apesar de a vacinação contra o FeLV não proteger o animal contra a infecção, esse procedimento evita que o mesmo desenvolva as apresentações clínicas da doença. Dessa forma, todos os gatos que estiverem expostos a algum fator de risco, como acesso livre à rua e contato com outros felinos de procedência desconhecida, devem ser vacinados (HOFMANN-LEHMANN et al. 1995, HARTMANN 2006).

Dentre as doenças infecciosas, a causada pelo FeLV foi a de maior representatividade, apresentando uma ocorrência, com relação ao número total de casos atendidos, de 13/825 (1,56\%). Estudos realizados, por meio da detecção do antígeno capsular p27 no sangue, demonstraram que a prevalência dessa doença varia muito em cada local. Na Europa, de 17.462 gatos testados, 3,6\% foram positivos para FeLV (GLEICH et al. 2009) e, na América do Norte, 2,3\% de 18.038 felinos foram positivos (LEVY et al. 2006), enquanto, no Zimbabwe, de 100 gatos testados, 41\% foram positivos (MUCHAAMBA et al. 2014). Os dados demonstram que, em países desenvolvidos, que implementaram práticas de controle e prevenção da doença, existe considerável diminuição na incidência de felinos infectados (SYKES, 2014). No Brasil, um estudo realizado 
em São Paulo demonstrou que, de 298 gatos, 12,5\% eram positivos para FeLV (HAGIWARA et al. 1997), e no Rio de Janeiro, a prevalência de infecção pelo vírus foi de $11,52 \%$ em 1.094 gatos (ALMEIDA et al. 2012). No entanto, essas prevalências foram obtidas por meio de análise sorológica de gatos sadios e doentes, diversamente deste levantamento, que leva em consideração felinos diagnosticados na fase sintomática da doença; por este motivo, o valor encontrado é inferior aos outros estudos.

Com relação aos critérios de classificação, o FeLV apresentou maior ocorrência em gatos SRD, de 1 a 7 anos (média de 1 ano e 10 meses), machos, com livre acesso à rua e que mantinham contato direto com outros felinos. Essas classes são consideradas, por diversos autores, como importantes fatores de risco facilitadores do contágio pelo vírus, com exceção do fator de risco raça, que parece não influenciar o acometimento de doenças causadas pelo FeLV (LEVY et al. 2006, ALMEIDA et al. 2012, MUCHAAMBA et al. 2014). A não vacinação contra o FeLV é reconhecidamente um fator de risco importante no que se refere ao desenvolvimento de doenças relacionadas ao FeLV (HOFMANN-LEHMANN et al. 1995, HARTMANN 2006) e, neste estudo, foi possível observar que nenhum animal havia recebido vacinas.

Os gatos infectados pelo FeLV desenvolveram a doença na forma de anemia, leucemia, linfoma e imunossupressão, que são as apresentações clínicas mais comuns causadas pelo vírus (LUTZ et al. 2009), assim como as alterações hematológicas, como anemia arregenerativa, leucopenia e linfopenia (ARJONA et al. 2000). O FeLV também é conhecido por um elevado número de óbitos (HARDY JUNIOR et al. 1976) e, neste trabalho, foi possível observar uma taxa de mortalidade de $91,31 \%$ relacionada ao vírus.

As doenças causadas por fungos, como a criptococose e a histoplasmose, também foram relatadas neste estudo. A criptococose é comum em gatos imunossuprimidos (CASTELLÁ et al. 2008), sendo o FeLV e o FIV os principais agentes causadores de imunossupressão, nesta espécie (LUTZ et al. 2009). Desta maneira, o status do animal quanto a essas infecções virais poderia auxiliar no diagnóstico e no tratamento do paciente. É importante ressaltar que esses fungos também são responsáveis por causar doença em humanos, sendo que a presença no ambiente urbano é também um fator de risco para os humanos imunossuprimidos (BERMEJO et al. 1998, PAPPALARDO \& MELHEM 2003, KON et al. 2008).

Dentre as doenças bacterianas, a micoplasmose foi a de maior ocorrência [3/33 (9,09\%)], sendo que todos os gatos acometidos eram machos e possuíam acesso livre à rua, fatores que são considerados importantes, aumentando o risco de infecção por hemoplasmas em felinos (WILLI et al. 2006, SOUSA et al. 2013). A patogenicidade dos hemoplasmas varia de acordo com a sua espécie, sendo que $M$. haemofelis é considerado o mais patogênico, levando ao desenvolvimento de hemólise e, consequentemente, anemia (WESTFALL et al. 2001), que foram as alterações clínicas e hematológicas encontradas.

Os protozoários tiveram baixa ocorrência entre as doenças infecciosas, porém é importante ressaltar que a Giardia sp. causa doença em outros animais domésticos e também no homem (CARVALHO 2009).

\section{CONCLUSÃO}

O vírus da leucemia felina foi o agente viral causador de doença mais prevalente neste estudo. Gatos machos e com livre acesso à rua apresentaram maior ocorrência de FeLV, demonstrando maior risco para esta população. A ocorrência de doenças infecciosas está intimamente relacionada à guarda responsável, sendo que a maioria dos gatos aqui estudados não havia recebido vacina, possuía livre acesso à rua $\mathrm{e}$ contato direto com outros gatos, fatores estes que facilitam a disseminação de doenças infecciosas. A observação destes dados demonstra a necessidade de maiores estudos sobre as doenças infecciosas nos gatos da região e também quanto à posse responsável desses animais, devido à crescente adesão aos felinos dentro do ambiente doméstico.

\section{REFERÊNCIAS}

ALMEIDA NR et al. 2012. Prevalence of feline leukemia virus infection in domestic cats in Rio de Janeiro. Journal of Feline Medicine and Surgery 14: 583-586.

ALVES MCGP et al. 2005. Dimensionamento da população de cães e gatos do interior do Estado de São Paulo. Revista de Saúde Pública 39: 891-897.

ARJONA A et al. 2000. Seroepidemiological survey of infection by feline leukemia virus and immunodeficiency virus in Madrid and correlation with some clinical aspects. Journal of Clinical Microbiology 38: 3448-3449.

BERMEJO A et al. 1998. Histoplasmosis: dificultades diagnósticas en una afección marcadora de SIDA. Dermatología argentina 4: 109-111.

BRÖMEL C \& SYKES JE. 2005. Histoplasmosis in dogs and cats. Clinical Techniques in Small Animal Practice 20: 227232.

CARVALHO TTR. 2009. Estado atual do conhecimento de Cryptosporidium e Giardia. Revista de Patologia Tropical 38: 1-16. 
CASTELLÁ G et al. 2008. Criptococosis y animales de compañía. Revista lberoamericana de Micología 25: $19-24$.

DEZENGRINI R et al. 2007. Soroprevalência das infecções por parvovírus, adenovírus, coronavírus canino e pelo vírus da cinomose em cães de Santa Maria, Rio Grande do Sul, Brasil. Ciência Rural 37: 183-189.

FORTNEY WD. 2008. Geriatria e senilidade. In: HOSKINS JD. Geriatria e gerontologia do cão e do gato. 2.ed. São Paulo: Roca. p.1-5.

GLEICH SE et al. 2009. Prevalence of feline immunodeficiency virus and feline leukaemia virus among client-owned cats and risk factors for infection in Germany. Journal of Feline Medicine and Surgery 11: 985-992.

GUNN-MOORE DA \& REED N. 2011. CNS disease in the cat: current knowledge of infectious causes. Journal of Feline Medicine and Surgery 13: 824-836.

HARDY JUNIOR WD et al. 1976. Biology of feline leukemia virus in the natural environment. Cancer Research 36: $582-$ 588.

HARTMANN K. 2006. Feline leukaemia virus infection. In: GREENE CG. Infectious disease of the dog and cat. 3.ed. Missouri: Elsevier. p.105-131.

HAGIWARA MK et al. 1997. Estudo clínico da infecção de felinos pelo vírus da leucemia felina em São Paulo. Revista Brasileira de Ciência Veterinária 4: 35-38.

HOFMANN-LEHMANN R et al. 1995. Recombinant FeLV vaccine: long-term protection and effect on course and outcome of FIV infection. Veterinary Immunology and Immunopathology 46: 127-137.

IBGE. 2015. Instituto Brasileiro de Geografia e Estatística. Pesquisa nacional de saúde 2013: Acesso e utilização dos serviços de saúde, acidentes e violências. Brasil, grandes regiões e unidades da federação. Rio de Janeiro: IBGE. 100p. Disponível em: http://biblioteca.ibge.gov.br/visualizacao/livros/liv94074.pdf. Acesso em: 4 set. 2016.

JANG SS \& WALKER RL. 2006. Laboratory diagnosis of fungal and algal infections. In: GREENE CE. Infectious Disease of the Dog and Cat. 3.ed. Missouri: Elsevier. p. 533-542.

KERL ME. 2003. Update on canine and feline fungal diseases. Veterinary Clinics of North America: Small Animal Practice 33: 721-747.

KON AS et al. 2008. Consenso em criptococose - 2008. Revista da Sociedade Brasileira de Medicina Tropical 41: 524 544.

LANGONI H et al. 2011. Conhecimento da população de Botucatu-SP sobre guarda responsável de cães e gatos. Veterinária e Zootecnia 18: 297-305.

LEVY JK et al. 2006. Seroprevalence of feline leukemia virus and feline immunodeficiency virus infection among cats in North America and risk factors for seropositivity. Journal of the American Veterinary Medical Association 228: 371-376.

LUTZ H et al. 2009. Feline leukaemia: ABCD guidelines on prevention and management. Journal of Feline Medicine and Surgery 11: 565-574.

MARTINS DB et al. 2008. Diagnóstico de criptococose canina pela citologia aspirativa por agulha fina. Ciência Rural 38: 826-829.

MUCHAAMBA F et al. 2014. A survey of feline leukaemia virus infection of domestic cats from selected areas in Harare, Zimbabwe. Journal of the South African Veterinary Association 85: 1-6.

PAPPALARDO MCSM \& MELHEM MSC. 2003. Cryptococcosis: a review of the brazilian experience for the disease. Revista do Instituto de Medicina Tropical de São Paulo 45: 299-305.

PENNISI MG et al. 2013. Cryptococcosis in cats: ABCD guidelines on prevention and management. Journal of Feline Medicine and Surgery 15: 611-618.

QUEIROZ JPAF et al. 2008. Criptococose - uma revisão bibliográfica. Acta Veterinaria Brasilica 2: 32-38.

SYKES JE. 2014. Feline immunodeficiency virus infection. In: SYKES JE. Canine and feline infectious diseases. Missouri: Elsevier. p. 209-210.

SYKES JE \& TABOADA J. 2014. Histoplasmosis. In: SYKES JE. Canine and feline infectious diseases. Missouri: Elsevier. p.587-598.

SOUSA SKSA et al. 2013. Diagnóstico molecular da infecção por hemoplasmas em gatos domésticos naturalmente infectados da cidade de Belém, Pará. Pesquisa Veterinária Brasileira 33: 1116-1120.

TASKER S. 2010. Haemotropic mycoplasmas: What's their real significance in cats? Journal of Feline Medicine and Surgery 12: 369-381.

TRAPP SM et al. 2010. Causas de óbito e razões para eutanásia em uma população hospitalar de cães e gatos. Brazilian Journal of Veterinary Research and Animal Science 47: 395-402.

TRIVEDI SR et al. 2011. Feline cryptococcosis: impact of current research on clinical management. Journal of Feline Medicine and Surgery 13: 163-172.

WESTFALL DS et al. 2001. Inoculation of two genotypes of Haemobartonella felis (California and Ohio variants) to induce infection in cats and the response to treatment with azithromycin. American Journal of Veterinary Research 62 : 687-691.

WILLI B et al. 2006. Prevalence, risk factor analysis, and follow-up of infections caused by three feline hemoplasma species in cats in Switzerland. Journal of Clinical Microbiology 44: 961-969. 